\title{
Optimal design of a climatological network: beyond practical considerations
}

\author{
G. S. Mauger ${ }^{1}$, K. A. Bumbaco ${ }^{2}$, G. J. Hakim ${ }^{3}$, and P. W. Mote ${ }^{4}$ \\ ${ }^{1}$ Climate Impacts Group, University of Washington, P.O. Box 355674, Seattle, WA 98195-5672, USA \\ ${ }^{2}$ Office of the Washington State Climatologist, University of Washington, P.O. Box 355672, Seattle, WA 98195-5672, USA \\ ${ }^{3}$ Department of Atmospheric Sciences, P.O. Box 351640, University of Washington, Seattle, WA 98195-1640, USA \\ ${ }^{4}$ College of Earth, Ocean, and Atmospheric Sciences, 104 CEOAS Admin Building, Oregon State University, \\ Corvallis, OR 97331, USA
}

Correspondence to: G. S. Mauger(gmauger@uw.edu)

Received: 2 January 2013 - Published in Geosci. Instrum. Method. Data Syst. Discuss.: 3 May 2013

Revised: 1 July 2013 - Accepted: 16 July 2013 - Published: 22 July 2013

\begin{abstract}
Station locations in existing environmental networks are typically chosen based on practical constraints such as cost and accessibility, while unintentionally overlooking the geographical and statistical properties of the information to be measured. Ideally, such considerations should not take precedence over the intended monitoring goal of the network: the focus of network design should be to adequately sample the quantity to be observed.

Here we describe an optimal network design technique, based on ensemble sensitivity, that objectively locates the most valuable stations for a given field. The method is computationally inexpensive and can take practical constraints into account. We describe the method, along with the details of our implementation, and present-example results for the US Pacific Northwest, based on the goal of monitoring regional annual-mean climate. The findings indicate that optimal placement of observing stations can often be highly counterintuitive, thus emphasizing the importance of objective approaches. Although at coarse scales the results are generally consistent, sensitivity tests show important differences, especially at smaller spatial scales. These uncertainties could be reduced with improvements in datasets and improved estimates of the measurement error. We conclude that the method is best suited for identifying general areas within which observations should be focused, and suggest that the approach could serve as a valuable complement to land surveys and expert input in designing new environmental observing networks.
\end{abstract}

\section{Introduction}

Environmental observing networks are established for a wide variety of purposes, ranging from short-term weather forecasting to monitoring ecosystem change. A compromise between scientific and practical considerations (e.g., site accessibility, cost, land ownership) usually governs the placement of stations, though practical considerations often have a greater influence on the final station locations. Historically, station site selection has typically been made subjectively, which suggests that the goals for the network are not met optimally or cost effectively. Theories for optimal observing networks have matured to the point where an objective costbenefit analysis can be considered when creating, augmenting, or revising an observing network. Objectivity is important because results show that optimally selected station locations often do not follow from intuition. Here we describe a flexible ensemble-based network-design algorithm that incorporates measurement error and can account for practical considerations such as accessibility of the site and land ownership.

An example of an observing network is the cooperative observer (COOP) weather network, which was established in the 19th century and remains the primary legacy network for climate monitoring in the United States. Since the COOP network relies heavily on volunteer observers, nearly all stations are situated in inhabited areas, and stations consequently tend to cluster in lower elevations. Installation and annual upkeep 
is more costly for remote stations, and these locations are often overlooked. For areas with complex terrain such as the western United States, low-lying networks near population centers do not accurately represent the climate in adjacent mountainous areas, especially for precipitation (Dabberdt and Schlatter, 1996). Variations in wind and sun exposure, cold air pooling in mountain valleys, and coastal fog are just a few examples of common weather occurrences that can result in sharp climate distinctions across fairly short distances (e.g., Lundquist and Cayan, 2007; Abatzoglou et al., 2009). As a result, it is possible for closely spaced stations to sample vastly different climates, or conversely, for two distant stations to be highly correlated and hence largely redundant. Prior studies have confirmed this (e.g., Fujioka, 1986; Hargrove et al., 2003), showing that uniformly spaced stations do not provide an advantage over those that are optimally placed. Fujioka (1986), for example, found that the optimal station locations were non-intuitive, and had 15 times less normalized error than the gridded locations in representing fire weather variables in southern CA.

Clearly, methods are needed that can help objectively identify compromises between scientific and practical considerations when designing and augmenting an observing network. By optimally determining the most valuable observation sites, the utility of a network can be maximized and the cost minimized as redundancy and guesswork in station placement is reduced.

\section{Methods}

\subsection{Ensemble sensitivity}

The ensemble sensitivity approach to network design is based on the idea of adaptive (or targeted) observations (e.g., Bergot et al., 1999; Morss et al., 2001; Bishop and Toth, 1999). Although the criteria are quite different, the same principles can be applied to the development of a fixed network for long-term monitoring. The problem centers on improving estimates of a scalar measure of interest, or "metric", $\boldsymbol{J}$. Applied to network design, the method (e.g., Khare and Anderson, 2006; Ancell and Hakim, 2007; Huntley and Hakim, 2010) works by iteratively finding sites that explain the most variance of a given climate field while accounting for the variance explained by previous "stations" selected (hereafter, the term "station" is used to refer to the optimal observing locations identified in the ensemble sensitivity approach). Finding the first station is relatively straightforward: it consists of identifying the point with the highest correlation with the metric while also maximizing the ratio of that correlation to the measurement error. Locating the second station is more difficult because the choice must account for the variance already explained by the first station. As discussed below, this is accomplished by using the Kalman update equation to adjust the sampled values at each grid point. The process then repeats: a new station is chosen, and the ensemble sample is adjusted to account for the new information that this station provides. With each chosen station, the variance in the data decreases according to the variance explained by the previous stations. At some point, very little additional variance is gained by identifying new stations, or alternatively, the remaining variance becomes indistinguishable from the noise. This point is reached when no new information is gained by adding stations beyond the number already identified (in Sect. 2.4 we describe our bootstrap approach to approximating this threshold). Note that the method is general: no specific time step, variables, or spatial configuration is required - this is a key strength of the approach. A brief description of the algorithm follows.

In ensemble sensitivity analysis, different samples of the state of the system $(\boldsymbol{x})$ are used to develop statistics that relate changes in the state of the system to changes in a particular metric of interest $(\boldsymbol{J})$. Using a gridded "truth" field as a proxy for observations, an optimally located observation is thus defined as the grid point that contributes most to the variance in $\boldsymbol{J}$, our metric of interest. We accomplish this by calculating the change in the variance of $\boldsymbol{J}\left(\Delta \sigma_{J}^{2}\right)$ for each grid point, and identifying the grid point for which this change is maximized. By using anomalies in the state of the system $(\boldsymbol{x})$ and a first-order Taylor expansion of $\boldsymbol{J}$, Ancell and Hakim (2007) show that $\Delta \sigma_{J}^{2}$ can be rewritten as follows:

$$
\begin{aligned}
\Delta \sigma_{J}^{2} & =\sigma_{J, i-1}^{2}-\sigma_{J, i}^{2} \\
& =\left[\frac{\partial \boldsymbol{J}}{\partial \boldsymbol{x}}\right]^{T} \mathbf{K}_{i} \mathbf{H}_{i} \mathbf{B}_{i-1}\left[\frac{\partial \boldsymbol{J}}{\partial \boldsymbol{x}}\right] \\
\mathbf{K}_{i} & =\mathbf{B}_{i-1} \mathbf{H}_{i}^{T} \mathbf{E}_{i}^{-1} \\
\mathbf{E}_{i} & =\mathbf{H}_{i} \mathbf{B}_{i-1} \mathbf{H}_{i}^{T}+R^{2},
\end{aligned}
$$

where $i$ refers to the $i$-th iteration of the algorithm, $\mathbf{B}_{i-1}$ is the prior error covariance of $\boldsymbol{x}, \mathbf{K}_{i}$ is the Kalman gain (Hamill, 2006; Kalman, 1960), $\mathbf{E}_{i}$ is the "innovation error covariance", and $R^{2}$ is the measurement error, which includes both instrument and "representativeness" error (error associated with sub-grid variability). $\mathbf{H}_{i}$ is a linearized observation operator, which maps the state of the system $(\boldsymbol{x})$ to an observation of interest. In Eq. (2), the change in the error covariance upon selection of the $i$-th station is estimated using the Kalman gain (Eq. 3) associated with the new observation.

As discussed above, the selection of the $i$-th station is conditioned on the variance explained by the previous $(i-1)$ stations. In matrix form, this conditional adjustment is applied using the classic Kalman update equation for the covariance matrix $\left(\mathbf{B}_{i}=\left(\mathbf{I}-\mathbf{K}_{i} \mathbf{H}_{i}\right) \mathbf{B}_{i-1}\right)$. The matrix implementation, however, has two principle disadvantages: (1) it can be numerically unstable, and (2) it is computationally expensive. As a result, we instead use the square root implementation of the Kalman update equation as follows: 


$$
\begin{aligned}
& \Delta \sigma_{J}^{2}=\frac{\operatorname{cov}\left(J, x_{m, i}\right)^{2}}{\sigma_{x_{m, i}}^{2}+R_{m}^{2}} \\
& x_{m, i}=x_{m, i-1}-\beta\left(\frac{\operatorname{cov}\left(x_{m, i-1}, x_{\mathrm{stn}, i-1}\right)}{\sigma_{x_{\mathrm{stn}, i-1}}^{2}+R_{m}^{2}}\right) x_{\mathrm{stn}, i-1} \\
& \beta=\frac{1}{1+\sqrt{\frac{R_{m}^{2}}{\sigma_{x_{\mathrm{stn}, i-1}^{2}+R_{m}^{2}}^{2}}}}
\end{aligned}
$$

where $x_{m}$ refers to the time series for an arbitrary grid point, $x_{\text {stn }}$ refers to the time series for the $i$-th selected station, and $\beta$ is a term that results from the conversion from matrix to square root form (Potter, 1964). These simplified equations arise from the fact that, in serial processing (i.e., the square root implementation), $\mathbf{H}_{i}$ is simply a vector that extracts the $m$ th grid point of $\boldsymbol{x}$ (i.e., $\mathbf{H}_{i}=[0,0, \ldots, 1, \ldots, 0]$; see Huntley and Hakim, 2010).

Although perhaps less elegant than in their matrix form, these equations help illustrate the logic behind the approach. First, note that Eq. (5) very closely resembles the square of the correlation between $\boldsymbol{J}$ and the time series at each grid point, the only differences being a missing constant $\left(\sigma_{J}^{2}\right)$ and an added error term $\left(R^{2}\right)$ in the denominator. At each step in the calculation, the optimal station is selected by identifying the grid point for which $\Delta \sigma_{J}^{2}$ is maximized. The error term serves to promote areas where the correlation with $\boldsymbol{J}$ is large compared to the measurement uncertainty. Second, note that Eq. (6) essentially uses an ordinary least squares regression, scaled by $\beta$, to adjust the sample values at each grid point $\left(x_{m}\right)$. The conditional adjustment is thus achieved by removing that portion of the variance in $x_{m}$ that can be reproduced using the time series of the selected station $\left(x_{\mathrm{stn}}\right)$. Finally, note that the parameter $\beta$ is always between 0.5 and 1 , and thus serves to reduce the adjustment to $x_{m}$, based on the proportion of grid cell variance to measurement uncertainty $\left(R^{2}\right)$.

The approach we have described rests on several key assumptions. Specifically, the Kalman update equation is only optimal if the following conditions are met:

1. Linear: the approach involves a linearization about the time-averaged state.

2. Gaussian: the model state variables (and associated noise) are Gaussian in distribution.

These assumptions are discussed in Sect. 2.2 below.

\subsection{Data}

We apply the approach to the problem of monitoring regionally and annually averaged precipitation and temperature over the US Pacific Northwest (hereafter "PNW"), which we define to span the three US states of Idaho, Oregon, and Washington (see Fig. 1). This is based loosely on the recent interest in improving climate monitoring across the US,

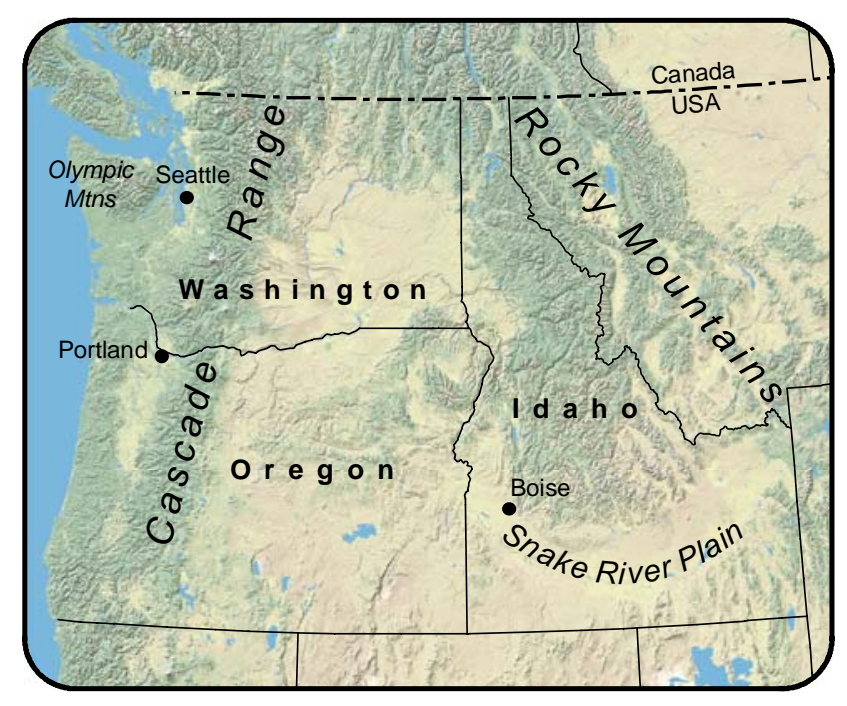

Fig. 1. Map of the study region, defined as the region encompassed by the US states of Idaho, Oregon, and Washington. The map and legend highlight several geographic features as well as the cities of Boise, Portland, and Seattle. The color scale shows elevation above sea level in meters.

as exemplified by the deployment of the Climate Reference Network (CRN) in the early 2000s. As we note above, although there are numerous observing stations throughout this region, the sampling is biased towards lower elevations and population centers, in all likelihood leaving important features of the regional climate unobserved. The purpose of the present exercise is thus to identify the locations where surface measurements would be most valuable, with regard to the goal of monitoring annual climate in the PNW. For simplicity we assume that we are designing the network from scratch and neglect practical considerations such as land ownership and access. The results thus identify the most valuable observing locations, irrespective of existing measurements or constraints on land use, access, etc. As discussed in the conclusions, the method can be easily adapted to incorporate such considerations.

In order to explore the sensitivity to the dataset used to define the stationary climate, we apply the method using three meteorological datasets listed in Table 1. PRISM (Daly et al., 2002) is created by gridding point observations and using an interpolation scheme that accounts for influences of terrain on climate including rain shadows, coastal effects, and temperature inversions. Annual temperature and precipitation data were obtained at $2.5 \operatorname{arcmin}(\sim 4 \mathrm{~km})$ resolution from the PRISM Climate Group website (www.prism. oregonstate.edu) for the years 1948-2011. Note that although PRISM data are available for 1895 to present, we chose to use only data from 1948 onward due to the greater station density in the latter part of the record. NARR (Mesinger et al., 2006) is an assimilated dataset covering North America from 1979 to present at a spatial resolution of $32 \mathrm{~km}$. Data were 
Table 1. Meteorological datasets used.

\begin{tabular}{lll}
\hline Dataset & Resolution & Notes \\
\hline PRISM: Parameter-elevation Regressions on Independent Slopes Model & $2.5 \operatorname{arcmin}(\sim 4 \mathrm{~km})$ & Daly et al. (2002) \\
NARR: North American Regional Reanalysis & $32 \mathrm{~km}$ & Mesinger et al. (2006) \\
GHCN: Global Historical Climatology Network, v 3.0 & N/A (point observations) & Lawrimore et al. (2011) \\
\hline
\end{tabular}

Table 2. Statistics of annual climate data for both temperature and precipitation. Results for precipitation are shown for both the raw data and after the transformation to Gaussian, as described in the text. For each statistic, the median for all grid cells is listed followed by the 5th and 95th percentile values in parentheses. Note that a Gaussian distribution has a skewness of 0 and a kurtosis of 3, but that with smaller sample sizes a discrete approximation to a Gaussian results in slightly lower values for the kurtosis.

\begin{tabular}{llllll}
\hline Variable & Source & Mean & Variance & Skewness & Kurtosis \\
\hline \multirow{2}{*}{ Temperature $\left({ }^{\circ} \mathrm{C}\right)$} & GHCN & $10.1(5.2,12.3)$ & $0.5(0.3,1.2)$ & $-0.4(-1.5,0.3)$ & $3.2(2.2,6.2)$ \\
& PRISM & $6.9(2.0,11.2)$ & $0.6(0.3,1.2)$ & $-0.1(-0.7,0.5)$ & $2.8(2.3,4.1)$ \\
& NARR & $7.8(2.2,11.9)$ & $0.6(0.2,1.1)$ & $-0.1(-0.7,0.3)$ & $2.7(2.0,4.0)$ \\
\hline \multirow{2}{*}{ Raw precip $\left(\mathrm{m} \mathrm{yr}^{-1}\right)$} & GHCN & $0.59(0.23,2.1)$ & $0.016(0.0039,0.21)$ & $0.6(-0.1,2.0)$ & $3.0(2.0,8.4)$ \\
& PRISM & $0.53(0.24,2.3)$ & $0.010(0.0034,0.16)$ & $0.4(-0.1,1.0)$ & $3.0(2.2,4.8)$ \\
& NARR & $0.56(0.26,1.9)$ & $0.015(0.0043,0.17)$ & $0.5(-0.2,1.1)$ & $2.8(2.0,4.3)$ \\
\hline \multirow{2}{*}{ Transformed precip } & GHCN & $0(0,0)$ & $0.015(0.0036,0.20)$ & $0(0,0)$ & $2.5(2.5,2.5)$ \\
& PRISM & $0(0,0)$ & $0.010(0.0033,0.15)$ & $0(0,0)$ & $2.7(2.7,2.7)$ \\
& NARR & $0(0,0)$ & $0.014(0.0043,0.16)$ & $0(0,0)$ & $2.5(2.5,2.5)$ \\
\hline
\end{tabular}

obtained from the National Climatic Data Center (NCDC; http://nomads.ncdc.noaa.gov/). GHCN is an integrated and quality-assured database of land surface stations (Lawrimore et al., 2011; stations included in the present analysis are listed in Table A1). Daily data were quality controlled by eliminating any temperature excursions that exceeded 5 standard deviations of all daily measurements for a specific calendar month, and any daily precipitation measurements that exceeded $254 \mathrm{~mm}$ (10 inches). Annual averages of GHCN observations were compiled from daily data by requiring a minimum of 10 days to compute a monthly average and 9 months to compute an annual average - different choices for these thresholds did not substantially impact the results. The 181 stations with complete records for 1979-2011 were included in the analysis.

Before proceeding, we assess the extent to which the data satisfy the two assumptions listed in the previous section, which are necessary conditions for applying the ensemble sensitivity approach. The first assumption, linearity, is not an issue for our application: since we intend to model precipitation and temperature using distributed observations of precipitation and temperature, our model simply consists of an average and is therefore linear.

The assumption of Gaussian statistics is worth investigating in some depth, in particular with regard to precipitation, which - even at annual timescales - exhibits a distribution that is skewed toward larger values. Table 2 lists the statistics of temperature, raw precipitation, and transformed precipitation data, showing the range of each statistic over all grid points. The transformed precipitation was created by remapping the observed cumulative distribution of precipitation to that of a normal distribution (by matching quantiles). To preserve the spatial variability in precipitation, the width of the normal distribution was scaled to match the variance of the observations. The transformation was performed separately for each grid cell since, although lumping all of the data together would improve sampling, it would not guarantee Gaussian statistics at each point. As can be seen in Table 2, the main impact of the precipitation transform is to eliminate any skewness in the data, though it is notable that the raw precipitation data is very nearly Gaussian as well. For this reason, our default in the calculations below is to use raw precipitation, though we note the impact of using transformed precipitation in the sensitivity tests discussed below.

\subsection{Measurement error}

The method takes into account measurement error (denoted $R^{2}$ in Eq. 3) resulting primarily from instrumental error and representativeness error, the latter being the error due to the fact that variability exists at the subgrid scale. Although in principle these quantities can be estimated, in practice such estimates are quite uncertain. In the present study, we use an empirically based estimate of the error variance in daily observations of surface temperature used by the European Centre for Medium-Range Weather Forecasting (ECMWF), of $3.6 \mathrm{~K}^{2}$. Assuming an autocorrelation timescale of 5 days, we obtain an annual error variance of about $0.05 \mathrm{~K}^{2}$ for annual 
average temperature. A constant value for $R^{2}$ is applied to all grid cells. Since measurements of precipitation are not generally assimilated in weather forecasting, there does not exist a similar estimate for the appropriate error variance in precipitation. As a result, we estimate the error variance for precipitation by simply rescaling the value used for temperature using the ratio of the variance in precipitation to the variance in temperature, and accounting for a precipitation autocorrelation timescale of 2 days instead of 5 . This corresponds to an error variance of $\sim 3.6 \%$ of the variance in precipitation at each grid cell and a median error variance of $375 \mathrm{~mm}^{2}$ (for total annual precipitation). Note that this is an approximation, since precipitation measurements are subject to different and often greater errors than for temperature. However, such differences are likely far less than the span of the sensitivity tests for $R^{2}$, described below. Finally, note that in contrast with temperature, $R^{2}$ is scaled with the grid cell variance in precipitation, since using a constant error variance would bias the results in favor of wetter regions.

Since both estimates of $R^{2}$ are approximations, we perform two simple verifications: (1) using raw surface observations from two nearby stations, and (2) using a gridded estimate of representativeness error. Note that in both cases we are assuming that the magnitude of $R^{2}$ is dominated by the representativeness error - a good assumption given that propagating the error in daily measurements of temperature and precipitation gives an annual instrument error of about $0.0001 \mathrm{~K}^{2}$ and $0.01 \mathrm{~mm}^{2}$, respectively.

In the first approach we consider the mean-squared difference between two nearby observing stations - Sea-Tac airport $\left(47.45^{\circ} \mathrm{N}, 122.3^{\circ} \mathrm{W}\right)$ and Kent COOP $\left(47.4^{\circ} \mathrm{N}\right.$, $122.2^{\circ} \mathrm{W}$ ) - for the overlapping time series spanning $1951-$ 2011. The result is a value of $0.28 \mathrm{~K}^{2}$ for temperature and $7800 \mathrm{~mm}^{2}$ for precipitation. Our central estimate for $R^{2}$ at that location is $\sim 950 \mathrm{~mm}^{2}$ for precipitation (and, as with all grid cells, $0.05 \mathrm{~K}^{2}$ for temperature). Note that the distance between these two observing stations is $7.5 \mathrm{~km}$, which is about twice the grid resolution of the PRISM dataset, making it likely that these numbers represent an overestimate of representativeness error

Our second approach to verifying the $R^{2}$ estimates from ECMWF is to use the 30 arc-seconds ( $~ 800 \mathrm{~m}$ resolution) climatologies available from PRISM to estimate the sub-grid variance in temperature and precipitation for each $2.5 \mathrm{arcmin}$ $(\sim 4 \mathrm{~km})$ grid cell. This gives an estimate of the representativeness error that varies with each grid cell, with a median of $0.06 \mathrm{~K}^{2}$ for temperature and $600 \mathrm{~mm}^{2}$ for precipitation. The corresponding values from ECMWF are $0.05 \mathrm{~K}^{2}$ for temperature, and $375 \mathrm{~mm}^{2}$ for precipitation, indicating that as above, the ECMWF-based estimates are somewhat conservative but well within the range of our sensitivity tests, discussed below.

\subsection{Sensitivity tests}

As the above discussion of measurement error highlights, several of the parameters used in applying the method are uncertain. Specifically, in addition to measurement error, the method may be sensitive to the choice of climate dataset, precipitation transform, the number of years included in the gridded data, the sample size (in years) for each calculation, and assumptions about the number of stations that the algorithm can meaningfully identify (i.e., as limited by sampling error). To address the sampling issues, we implemented a Monte Carlo routine in which the algorithm was run 50000 times, using a different random sample of years for each iteration. The Monte Carlo approach also addresses the question of noise limitations, since statistics can be obtained on the consistency of results between iterations (see discussion below). To test robustness to other parameters, we performed the following sensitivity tests: measurement error variance $\left(R^{2}\right)$ was scaled by a factor ranging from 0.1 to 10 , calculations were repeated for different climate datasets, precipitation transforms, sample sizes (ranging from 20 to $40 \mathrm{yr}$ ), and years from which to draw samples (1948-1979 vs. $1980-2011)$.

\section{Results and discussion}

Figure 2 shows the best estimate of the optimal observing locations, obtained using the following choices of data and parameters:

- metric $(\boldsymbol{J})$ : regionally averaged annual temperature and precipitation;

- dataset: PRISM;

- years: 1948-2011;

- sample size: $30 \mathrm{yr}$;

- $R^{2}=0.05 \mathrm{~K}^{2}$ for temperature;

- $R^{2}=3.6 \%$ of the grid cell variance in precipitation;

- precipitation: raw data (not transformed).

In this section we discuss these results along with the results of our sensitivity tests, which evaluate the impact of varying the above parameters and assumptions.

We summarize the results by producing maps that show the frequency, among all Monte Carlo iterations, with which a grid point is selected in the top "N" stations, where " $\mathrm{N}$ " is chosen to correspond to some average total variance explained in regional temperature or precipitation (see below). This accounts for sample variability while highlighting areas that are most likely to contribute optimally to monitoring regional climate. The result is a frequency value for each grid point, which can then be mapped as shown in Fig. 2. 

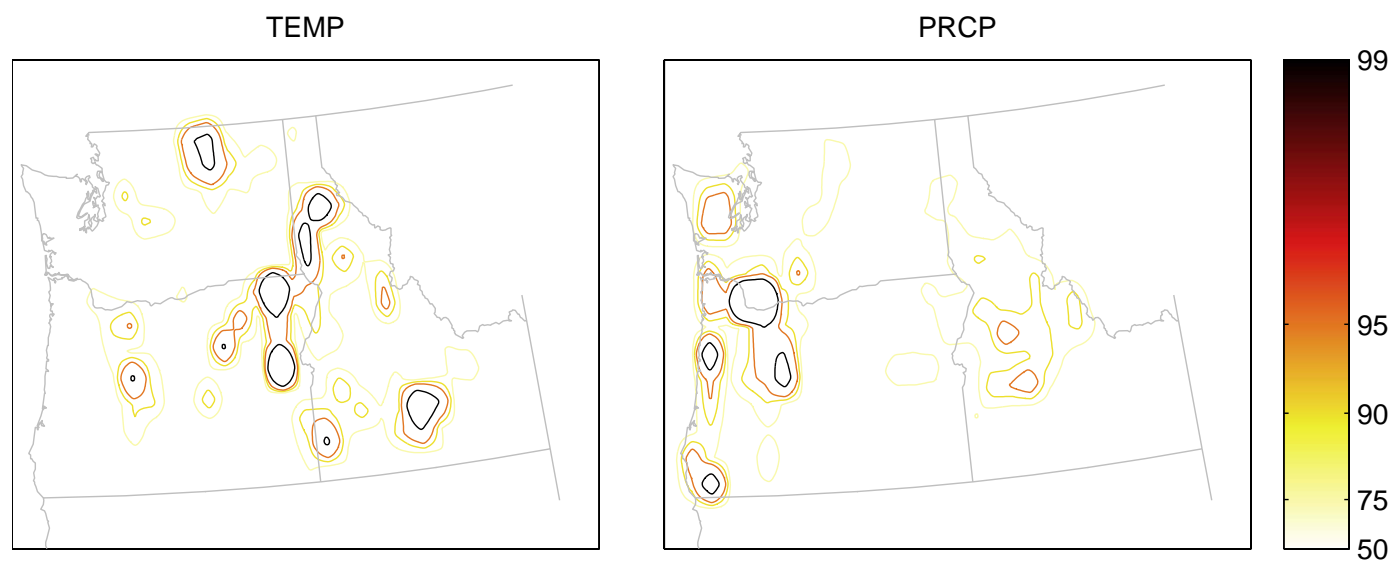

Fig. 2. Results for annual temperature and precipitation, obtained using the optimal network design calculation. Calculations were performed using regionally averaged temperature and precipitation as the target metric (defined as the average over the US states of Idaho, Oregon, and Washington). Contours show the percentile value of the grid cell weighting - higher weights denote areas where measurements contribute more to the variance explained. Results are obtained using the PRISM dataset (1948-2011), central estimates for the measurement error $\left(R^{2}\right)$, and a sample size of $30 \mathrm{yr}$.

Since these frequency values are most meaningful in a relative sense - which grid cells have greater weightings than others - we display the percentile values of the grid cell weightings, which we consider more helpful for interpretation. For example, a point is assigned a 95th percentile value if its frequency value - the fraction of Monte Carlo iterations in which it was selected in the top "N" points - is greater than or equal to that of $95 \%$ of all other points. Finally, in this and subsequent maps stemming from gridded PRISM data, the results have been averaged from $2.5 \operatorname{arcmin}(\sim 4 \mathrm{~km})$ resolution to 0.5 degree resolution. This smoothing is applied to aid in interpretation.

In order to choose "N" we look at the change in the variance explained as the calculation progresses - in other words, the percent of the variance in the metric (regional temperature or precipitation) that can be reproduced using a linear combination of the already-chosen stations. Table 3 lists the mean variance explained for both temperature and precipitation, for each additional station selection, for the results mapped in Fig. 2. As described in Sect. 2.1, the calculation proceeds by selecting stations that maximize the residual variance explained - in other words, that maximize the additional value lent by their selection. Table 3 illustrates that, due to high spatial autocorrelation across the region (in particular at annual timescales), the first station explains a majority of the variance, while subsequent stations account for progressively less of the residual variance. By summing the variance explained at each step, we find that, on average, the top 3 stations in temperature and the top 2 in precipitation are sufficient to explain $95 \%$ of the variance in the annual climate signal for the PNW. Similarly, to explain $99 \%$ of the variance would require selection of the top 11 and 4 stations for temperature and precipitation, respectively. For simplicity, we only show results for the former (i.e., $95 \%$ variance
Table 3. Percent of the variance explained with each station selection. Values shown are the median and 5th-95th percentile values (in parentheses) based on all 50000 Monte Carlo calculations.

\begin{tabular}{lll}
\hline \multirow{2}{*}{ Station \# } & \multicolumn{2}{c}{ Variance explained $(\%)$} \\
\cline { 2 - 3 } & Temperature & Precipitation \\
\hline 01 & $86.68(82.18-89.57)$ & $88.08(83.50-91.21)$ \\
02 & $6.71(05.00-09.30)$ & $6.70(04.20-11.08)$ \\
03 & $2.36(01.68-03.41)$ & $2.72(01.62-04.38)$ \\
04 & $1.13(00.80-01.66)$ & $1.23(00.69-02.18)$ \\
05 & $0.66(00.47-00.97)$ & $0.65(00.36-01.22)$ \\
06 & $0.43(00.31-00.63)$ & $0.39(00.21-00.74)$ \\
07 & $0.30(00.22-00.44)$ & $0.25(00.13-00.48)$ \\
08 & $0.22(00.16-00.32)$ & $0.16(00.08-00.32)$ \\
09 & $0.17(00.13-00.25)$ & $0.11(00.06-00.22)$ \\
10 & $0.14(00.10-00.19)$ & $0.08(00.04-00.16)$ \\
11 & $0.11(00.08-00.16)$ & $0.06(00.03-00.12)$ \\
12 & $0.09(00.07-00.13)$ & $0.05(00.02-00.09)$ \\
13 & $0.08(00.06-00.11)$ & $0.04(00.02-00.07)$ \\
14 & $0.06(00.05-00.09)$ & $0.03(00.01-00.06)$ \\
15 & $0.06(00.04-00.08)$ & $0.02(00.01-00.05)$ \\
16 & $0.05(00.04-00.07)$ & $0.02(00.01-00.04)$ \\
17 & $0.04(00.03-00.06)$ & $0.02(00.01-00.03)$ \\
18 & $0.04(00.03-00.05)$ & $0.01(00.01-00.03)$ \\
19 & $0.03(00.03-00.05)$ & $0.01(00.01-00.03)$ \\
20 & $0.03(00.02-00.04)$ & $0.01(00.00-00.02)$ \\
\hline & &
\end{tabular}

explained) in Fig. 2 and all subsequent figures. The results for different choices are qualitatively similar.

The results shown in Fig. 2 highlight several regions that are important for capturing the regional signal of climate variability. The results for temperature, for instance, highlight the central Snake River plain in Idaho, the mountains of northeast Oregon, and north-central Washington, among 
other regions (see Fig. 1 for a key to the geography of the region). For precipitation, the results are quite different, primarily highlighting the central Cascades, the Columbia gorge near Portland, the southeastern slopes of the Olympic mountains in Washington, and certain parts of the coast of Oregon. Notably, the optimal locations for monitoring temperature are almost entirely east of the Cascade mountains, while the opposite is true for the optimal observing locations identified for precipitation. In addition, some of the results are quite counterintuitive. For instance, while it makes sense that precipitation monitoring will maximize signal to noise on the substantially wetter western slopes of the Cascade mountains, it is not intuitively obvious that the central Cascade mountains are more appropriate than any other portion of this mountain range, nor is it clear why the even wetter western slopes of the Olympic mountains are hardly highlighted at all.

Figure 3 shows a comparison of results obtained from the three datasets: GHCN, NARR, and PRISM. In order to perform a direct comparison, NARR and PRISM data were only used for the grid points that correspond most closely to the location of each GHCN station, and all datasets applied to the years 1979-2011 only, with a sample size of $20 \mathrm{yr}$ for each calculation. The $R^{2}$ values applied to each case were identical. Note that this is not a perfect comparison, since point measurements (i.e., GHCN) are different from grid-cell averages (NARR, $32 \mathrm{~km}$ resolution; PRISM, $\sim 4 \mathrm{~km}$ resolution).

The rank correlations between the GHCN results and each gridded dataset are shown in the upper right-hand corner of each map. Since disagreement among adjacent stations could confound the results, we calculated correlations by first averaging the point results for each dataset onto a 0.5 degree grid. Point correlations (not shown) were significant but substantially lower than their gridded counterparts. We use rank correlations because the results are highly skewed, causing standard correlations to be disproportionately affected by a small number of points. Since our emphasis in this work is on the relative rankings among grid points, we deem the rank correlations a better measure of similarities among the results. Standard correlations also revealed significant positive correlations, but nonetheless lower values.

A number of observations can be made from these results. First, at coarse scales (i.e., the broad regions highlighted) there is good agreement among the three datasets. Second, PRISM and GHCN bear the greatest similarities, a fact which is perhaps not surprising given that PRISM is essentially a regridding of surface observations. Third, although the general picture remains consistent between datasets, the specific rankings can differ substantially (as reflected in the correlations). Since the three agree well at coarser spatial scales, this suggests that the discrepancies are primarily in the treatment of climate variations across smaller scales. We thus conclude that, until well-validated improvements in datasets become available, the results are best viewed as defining broad regions within which to focus efforts. Based on this comparison, Fig. 2 and all subsequent results are shown using the PRISM dataset, averaged to 0.5 degree resolution (i.e., calculations are performed at the native PRISM resolution of $\sim 4 \mathrm{~km}$, then averaged to 0.5 degree resolution for presentation).

A primary advantage of our approach is that it is objective, and that it is therefore capable of highlighting non-intuitive but nonetheless optimal observing locations. However, implementation of the method does entrain a number of important subjective decisions, as highlighted at the beginning of this section. Figures 4 and 5 show how the results are affected by varying the parameters chosen for the calculation. Specifically, we test for the influence of variations in the sample size ( 20 vs. $40 \mathrm{yr}$ ), the years from which to draw a sample (1948-1979 vs. 1980-2011), and the value for the total error variance $\left(R^{2} ; 10\right.$ times smaller vs. 10 times larger than our central estimate) in temperature (Fig. 4) and precipitation (Fig. 5). Note that changing the values of $R^{2}$ changes the number of stations ("N") needed to achieve $95 \%$ variance explained - these were adjusted accordingly in the maps showing sensitivity to $R^{2}$. Note, also, that we do not consider variations in the metric $(\boldsymbol{J})$ - this would by definition alter the results, but would not inform our question regarding the robustness of the method.

Overall, as with Fig. 3, these results show broad consistencies across different parameter values, highlighting similar areas for monitoring despite large variations in parameters. Precipitation results appear to be much more robust than those for temperature. For both variables, the results are largely insensitive to the choice of sample size, but indicate a fair sensitivity to the choice of years sampled and, in particular, to $R^{2}$. The magnitude of $R^{2}$ impacts the extent to which the correlation with $\boldsymbol{J}$ is balanced by the ratio of signal-to-noise: small values for $R^{2}$ favor areas that correlate best with the regional signal, while large values of $R^{2}$ favor areas with higher variance. Even in the case of $R^{2}$, it is notable that the dominant regions highlighted nearly always correspond to regions that are also highlighted in Fig. 2.

For precipitation, we also considered the influence of holding $R^{2}$ constant across the domain and of applying a Gaussian transform to the precipitation results. Although not shown, the results using transformed precipitation correlated highly ( $r=0.85$; as above, we computed rank correlations after regridding to 0.5 degree) with the original results, indicating that at annual timescales the raw data are sufficiently Gaussian. Results obtained by using constant measurement error were less similar $(r=0.57)$, with differences largely resulting from the greater influence of regions west of the Cascade mountains. These differences are anticipated, since there are sharp changes in precipitation across the region, and a constant $R^{2}$ will favor regions with greater accumulation. 


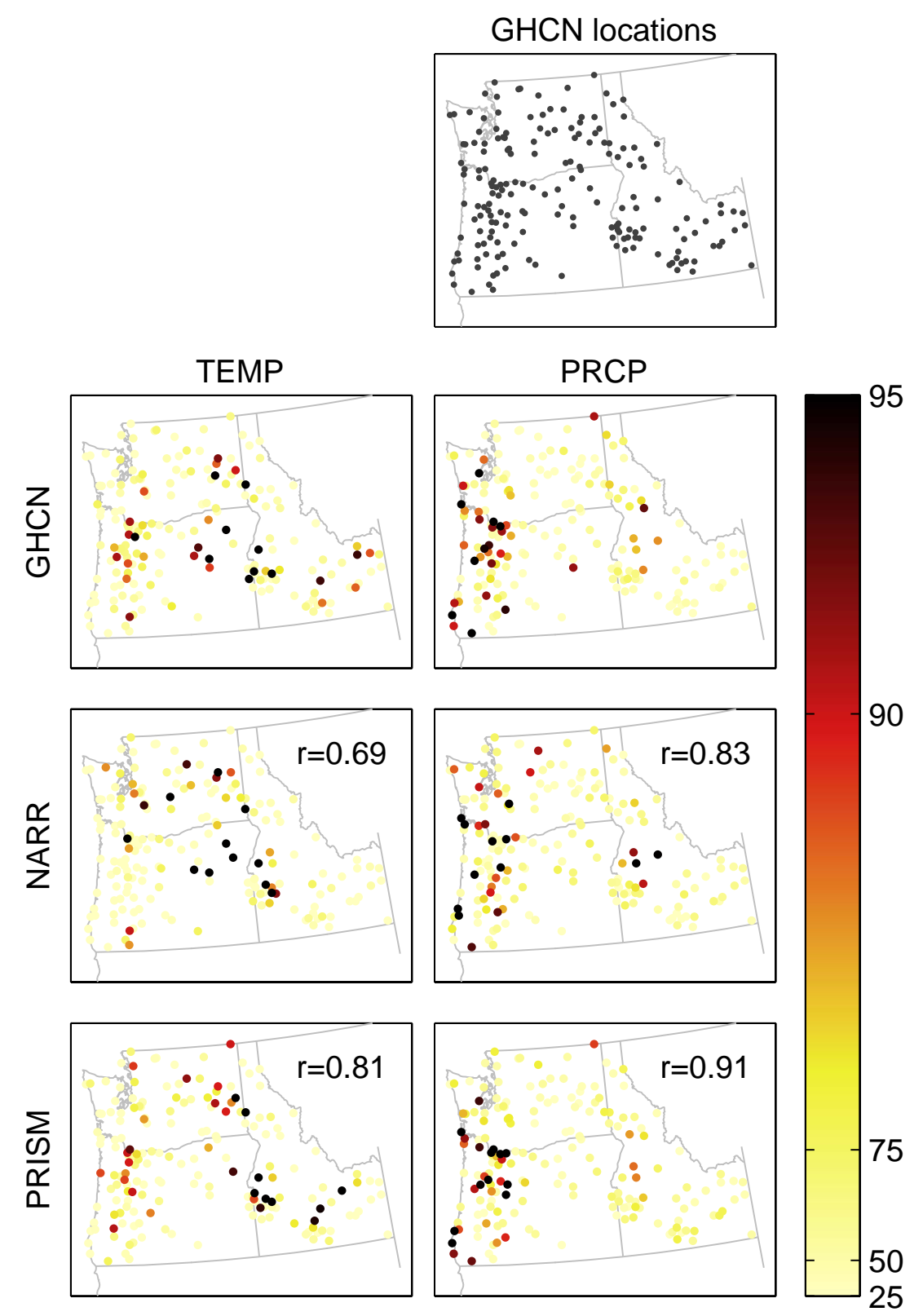

Fig. 3. Results from three different datasets (GHCN, NARR, PRISM), calculated for the $181 \mathrm{GHCN}$ stations with continuous records for the period 1979-2011. The top map, labeled "GHCN locations", shows the location of the GHCN stations used in the calculation. The 6 other maps show results for the different datasets. Each dot denotes the location of a GHCN station, and is shaded according to the percentage of time the station was chosen using the network design algorithm. Rank correlations with the GHCN results are shown in the top right corner of the NARR and PRISM maps. As with Fig. 2, percentile values are plotted to simplify interpretation. Note that, unlike in other figures, the color scale remains a light yellow at low values, and does not fade to white.

\section{Conclusions}

The ensemble sensitivity approach provides an objective method for allocating resources to develop an observational network. It allows for rapid evaluation of different metrics, and requires only a climatological sample. Since the utility of each observation is maximized, optimal placement ensures an efficient use of resources. There are two salient features to the approach: (1) stations are selected based on a compromise between their correlation with the metric and the ratio of signal-to-noise, and (2) new selections are constrained to minimize redundancy by maximizing the additional variance explained.

We present an example in which the goal is to optimally monitor regional climate in the US Pacific Northwest. Our analysis suggests that this goal can be achieved with 5 to 


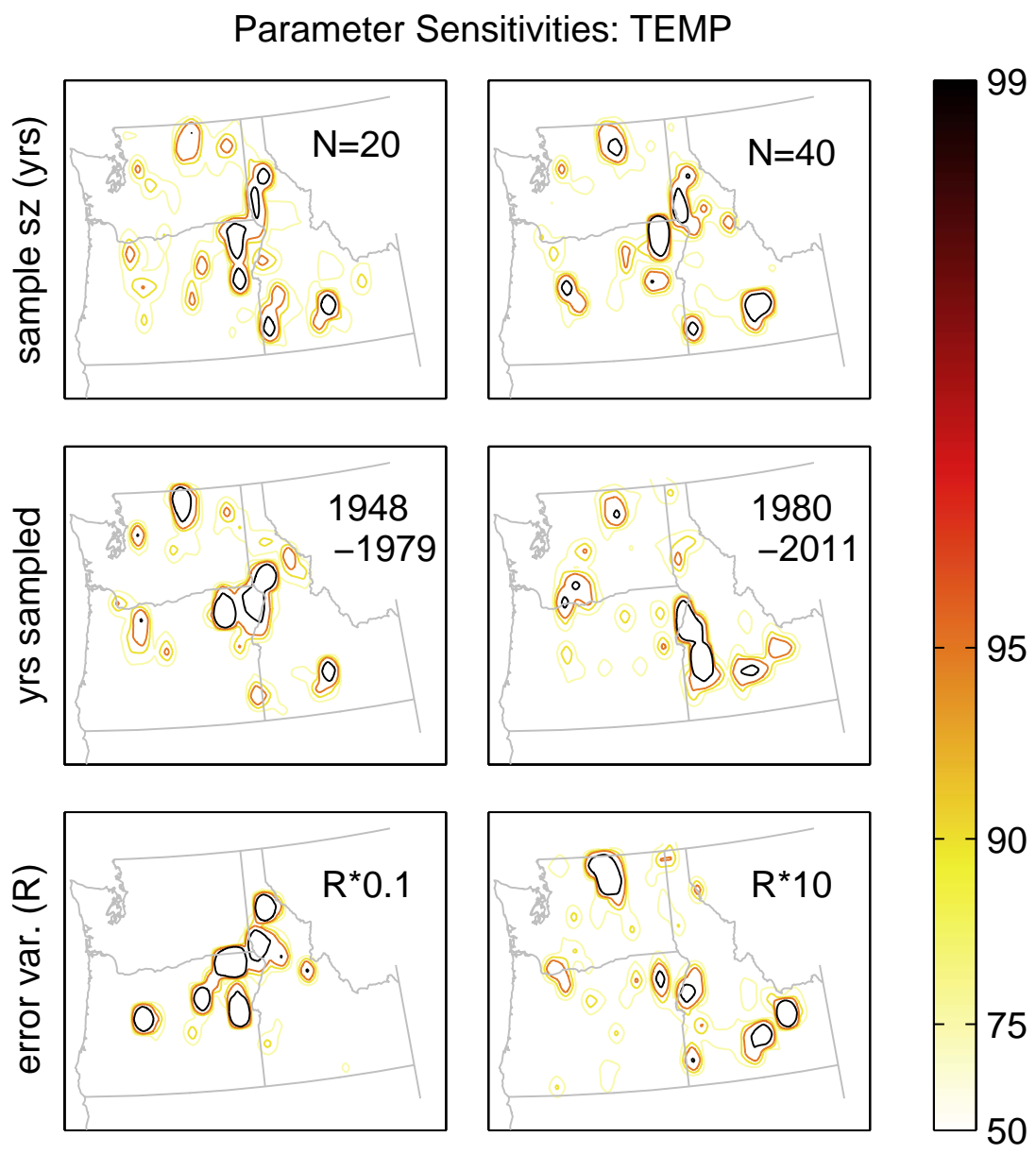

Fig. 4. Sensitivity of network design results for annual temperature, obtained by varying the parameters used to apply the algorithm. The top row shows results in which the sample size is varied between 20 and $40 \mathrm{yr}$, the middle row shows results obtained from the first half of the record (1948-1979) and the last half (1980-2011), and the bottom row shows the impact of scaling the measurement error $\left(R^{2}\right)$ by an order of magnitude in each direction.

10 optimally placed stations. We find that station placement is not intuitive, highlighting the importance of employing objective methods for network design. Note that this information can be used in one of two ways: (1) install only 5-10 new observing stations instead of the total number planned, or (2) pursue other monitoring goals (e.g., monitoring sub-regional climate(s), seasonal climate, or probability of extremes).

Sensitivity tests indicate that the results are robust to the choice of sample size and time period analyzed, but that there are important differences resulting from the choice of dataset and assumed measurement error $\left(R^{2}\right)$. Sensitivity to $R^{2}$ is fairly strong, but in general does not result in the identification of new regions for monitoring. Differences among datasets are likely partially attributable to differences in spatial resolution and the distinction between point measurements and grid cell averages. However, it is also likely that these differences represent real differences in the modeled covariability of temperature and precipitation across the region. Fortunately, the differences among datasets largely result from small spatial scale distinctions between each: the broad-scale patterns are consistent. Since important differences do exist, we conclude that until an improved dataset becomes available, the method is best used to identify general areas in which to locate stations. In practice, this is unlikely to be a limitation, since siting decisions at local scales are dominated by practical constraints such as land ownership, access, etc.

The example we present pertains to climate monitoring, and the approach assumes stationarity in the relationship between temperature and precipitation variations across the region. It is therefore worth considering whether the nonstationarity of the climate would impact the value of the network under climate change. The approach uses the covariance structure to identify optimal observing locations, which is primarily affected by terrain features: elevation, aspect, proximity to the coast, etc. Since these will not change with a changing climate - future storms will still come from the 


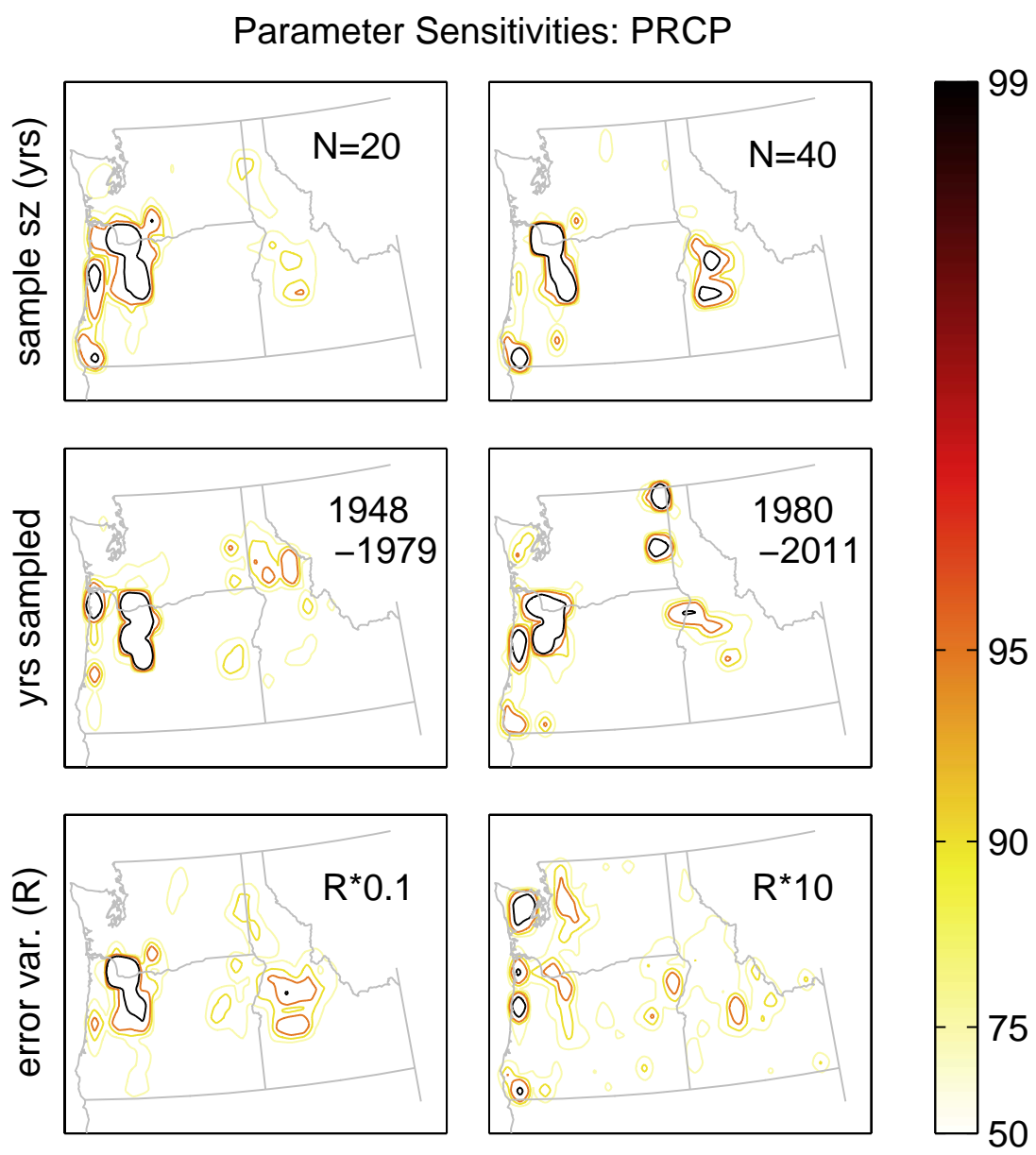

Fig. 5. As in Fig. 4 except applied to annual precipitation.

west, temperatures in the interior will still be more variable than at the coasts, etc. - we do not believe that this is a major concern. Furthermore, the assumption that the statistical relationships will remain the same with a changing climate is common in climate research (e.g., statistical downscaling, paleoclimate reconstructions). Moreover, an alternative approach, such as using GCM simulations, would have its own set of caveats in this regard (bias, coarse resolution, etc.).

A primary advantage of the ensemble sensitivity method is that it can be modified in a way that takes into account practical and scientific considerations while ensuring that the network maximizes return on investment. For instance, there are important practical constraints on station siting, such as land ownership, proximity to roads, and the presence of existing stations. These are easily incorporated into the calculations by (a) constraining the first " $n$ " station selections to correspond to existing observations, and (b) simply masking out grid cells that do not conform to the selection criteria. Furthermore, climatological networks are not designed to monitor just one quantity, and it is not necessarily the case that sites that capture a large fraction of the variance in precipitation should also be useful for monitoring other variables. The method could be made to iteratively select temperature and precipitation stations, making each conditional on the other. Flexibility is a key advantage of this approach: it can be easily adapted to the practical constraints of station siting while still ensuring that the monitoring goals are pursued optimally.

There are numerous potential applications for the ensemble sensitivity method spanning multiple fields, monitoring goals, and regions of interest. The advantage of optimal design is that it ensures an efficient use of resources. We believe that this approach can be a useful tool for informing decisions in network design.

Acknowledgements. Funding for this research was provided in part by NSF Grant 1043090, as well as the State of Washington through funding to the Office of Washington State Climatologist.

Edited by: L. Vazquez 
Table A1. GHCN station attributes.

\begin{tabular}{|c|c|c|c|c|c|c|}
\hline ID & Latitude & Longitude & Elevation $(\mathrm{m})$ & US state & Station name & Notes \\
\hline USC00100010 & 42.9536 & -112.8253 & 1342.6 & ID & ABERDEEN EXP STN & $\mathrm{HCN}^{\mathrm{a}}$ \\
\hline USC00100667 & 47.9803 & -116.5594 & 636.1 & ID & BAYVIEW MODEL BASIN & \\
\hline USC00101017 & 43.7383 & -116.2022 & 1184.1 & ID & BOISE $7 \mathrm{~N}$ & \\
\hline USC00101018 & 43.5253 & -116.0542 & 865.6 & ID & BOISE LUCKY PEAK DAM & \\
\hline USC00101220 & 42.6006 & -114.7453 & 1158.2 & ID & BUHL \#2 & \\
\hline USC00101363 & 48.0864 & -116.0572 & 662.3 & ID & CABINET GORGE & \\
\hline USC00101408 & 44.5733 & -116.6753 & 807.7 & ID & CAMBRIDGE & $\mathrm{HCN}$ \\
\hline USC00101514 & 44.5228 & -116.0481 & 1492.3 & ID & CASCADE $1 \mathrm{NW}$ & \\
\hline USC00101551 & 42.5503 & -114.8661 & 1165.9 & ID & CASTLEFORD $2 \mathrm{~N}$ & \\
\hline USC00101671 & 43.9772 & -113.8289 & 1908.0 & ID & CHILLY BARTON FLAT & \\
\hline USC00102260 & 43.4650 & -113.5581 & 1797.4 & ID & CRATERS OF THE MOON & \\
\hline USC00102444 & 43.5764 & -116.7475 & 765.0 & ID & DEER FLAT DAM & \\
\hline USC00102707 & 44.2436 & -112.2006 & 1661.2 & ID & DUBOIS EXP STN & \\
\hline USC00102845 & 46.5022 & -116.3217 & 303.3 & ID & DWORSHAK FISH HATCH & $\mathrm{HCN}$ \\
\hline USC00102875 & 45.8356 & -115.4611 & 1236.9 & ID & ELK CITY 1NE & \\
\hline USC00102942 & 43.8544 & -116.4664 & 728.5 & ID & EMMETT 2 E & \\
\hline USC00103143 & 46.0931 & -115.5356 & 475.5 & ID & FENN RS & $\mathrm{HCN}$ \\
\hline USC00103297 & 43.0428 & -112.4133 & 1360.9 & ID & FT HALL 1 NNE & \\
\hline USC00103631 & 42.9403 & -115.3231 & 751.6 & ID & GLENNS FERRY & $\mathrm{HCN}$ \\
\hline USC00103771 & 45.9414 & -116.1175 & 1005.8 & ID & GRANGEVILLE & \\
\hline USC00103964 & 43.9664 & -112.2642 & 1460.0 & ID & HAMER 4 NW & \\
\hline USC00104140 & 42.5972 & -114.1378 & 1237.5 & ID & HAZELTON & $\mathrm{HCN}$ \\
\hline USC00104295 & 42.3528 & -114.5739 & 1379.2 & ID & HOLLISTER & $\mathrm{HCN}$ \\
\hline USC00104384 & 43.7828 & -113.0033 & 1469.1 & ID & HOWE & \\
\hline USC00104442 & 43.8383 & -115.8319 & 1208.5 & ID & IDAHO CITY & \\
\hline USC00104456 & 43.3456 & -111.7847 & 1776.4 & ID & IDAHO FALLS 16 SE & \\
\hline USC00104670 & 42.7325 & -114.5192 & 1140.0 & ID & JEROME & $\mathrm{HCN}$ \\
\hline USC00104831 & 47.5339 & -116.1222 & 724.5 & ID & KELLOGG & $\mathrm{HCN}$ \\
\hline USC00104845 & 43.6842 & -114.3603 & 1795.3 & ID & KETCHUM RS & $\mathrm{HCN}$ \\
\hline USC00105275 & 42.1231 & -111.3139 & 1806.2 & ID & LIFTON PUMPING STN & $\mathrm{HCN}$ \\
\hline USC00105708 & 44.8872 & -116.1047 & 1531.6 & ID & MC CALL & \\
\hline USC00105897 & 44.7189 & -115.0150 & 1365.5 & ID & MIDDLE FORK LODGE & \\
\hline USC00106152 & 46.7281 & -116.9558 & 810.8 & ID & MOSCOW U OF I & $\mathrm{HCN}$ \\
\hline USC00106305 & 43.6039 & -116.5753 & 752.9 & ID & NAMPA SUGAR FACTORY & $\mathrm{HCN}$ \\
\hline USC00106542 & 42.2342 & -113.8981 & 1389.6 & ID & OAKLEY & $\mathrm{HCN}$ \\
\hline USC00106844 & 43.8022 & -116.9442 & 698.0 & ID & PARMA EXP STN & \\
\hline USC00106891 & 44.0764 & -116.9311 & 655.3 & ID & PAYETTE & $\mathrm{HCN}$ \\
\hline USC00107040 & 43.3111 & -114.0742 & 1472.2 & ID & PICABO & \\
\hline USC00107046 & 46.4922 & -115.8006 & 938.8 & ID & PIERCE & \\
\hline USC00107320 & 46.5100 & -114.7111 & 1075.9 & ID & POWELL & \\
\hline USC00107386 & 48.3511 & -116.8353 & 722.7 & ID & PRIEST RIVER EXP STN & $\mathrm{HCN}$ \\
\hline USC00107648 & 43.2064 & -116.7494 & 1197.9 & ID & REYNOLDS & \\
\hline USC00108022 & 43.9517 & -111.6789 & 1496.6 & ID & SAINT ANTHONY & \\
\hline USC00108080 & 45.1875 & -113.9008 & 1198.2 & ID & SALMON-KSRA & $\mathrm{HCN}$ \\
\hline USC00108380 & 42.9383 & -114.4169 & 1204.0 & ID & SHOSHONE 1 WNW & \\
\hline USC00108928 & 43.2436 & -116.3783 & 708.7 & ID & SWAN FALLS P H & \\
\hline USC00108937 & 43.4447 & -111.2939 & 1633.7 & ID & SWAN VALLEY 2 E & \\
\hline USC00109065 & 43.8564 & -111.2769 & 1880.6 & ID & TETONIA EXP STN & \\
\hline USC00109303 & 42.5458 & -114.3461 & 1207.0 & ID & TWIN FALLS 6 E & \\
\hline USC00109846 & 46.2381 & -116.6233 & 1210.7 & ID & WINCHESTER & \\
\hline USC00350304 & 42.2128 & -122.7144 & 532.2 & OR & ASHLAND & $\mathrm{HCN}$ \\
\hline USC00350471 & 43.1497 & -124.4019 & 6.1 & OR & BANDON 2 NNE & \\
\hline USC00350652 & 44.2867 & -122.0386 & 655.9 & OR & BELKNAP SPRINGS $8 \mathrm{~N}$ & \\
\hline USC00350694 & 44.0567 & -121.2850 & 1115.6 & OR & BEND & $\mathrm{HCN}$ \\
\hline USC00350897 & 45.6361 & -121.9519 & 18.9 & OR & BONNEVILLE DAM & \\
\hline USC00351433 & 44.3914 & -122.4811 & 292.6 & OR & CASCADIA & $\mathrm{HCN}$ \\
\hline USC00351448 & 42.1597 & -123.6422 & 419.7 & OR & CAVE JUNCTION 1 WNW & \\
\hline
\end{tabular}


Table A1. Continued.

\begin{tabular}{|c|c|c|c|c|c|c|}
\hline ID & Latitude & Longitude & Elevation (m) & US state & Station name & Notes \\
\hline USC00351643 & 46.1081 & -123.2058 & 6.7 & OR & CLATSKANIE & \\
\hline USC00351765 & 45.2325 & -120.1817 & 865.6 & OR & CONDON & $\mathrm{HCN}$ \\
\hline USC00351836 & 43.1872 & -124.2025 & 7.0 & OR & COQUILLE CITY & \\
\hline USC00351862 & 44.6342 & -123.1900 & 68.6 & OR & CORVALLIS STATE UNIV & $\mathrm{HCN}$ \\
\hline USC00351877 & 44.5078 & -123.4575 & 180.4 & OR & CORVALLIS WATER BUREAU & \\
\hline USC00351902 & 43.7178 & -123.0578 & 253.3 & OR & COTTAGE GROVE DAM & \\
\hline USC00351946 & 42.8967 & -122.1328 & 1973.6 & OR & CRATER LAKE NPS HQ & $\mathrm{HCN}$ \\
\hline USC00352112 & 44.9464 & -123.2908 & 88.4 & OR & DALLAS $2 \mathrm{NE}$ & \\
\hline USC00352173 & 44.5564 & -119.6447 & 688.8 & OR & DAYVILLE 8 NW & \\
\hline USC00352292 & 44.7242 & -122.2547 & 371.9 & OR & DETROIT DAM & \\
\hline USC00352406 & 43.6656 & -123.3275 & 89.0 & OR & DRAIN & $\mathrm{HCN}$ \\
\hline USC00352693 & 45.2689 & -122.3186 & 137.2 & OR & ESTACADA 2 SE & \\
\hline USC00353047 & 44.4139 & -122.6728 & 167.6 & OR & FOSTER DAM & \\
\hline USC00353356 & 42.4036 & -124.4242 & 15.2 & OR & GOLD BEACH RS & \\
\hline USC00353402 & 45.3014 & -121.7417 & 1213.1 & OR & GOVERNMENT CAMP & \\
\hline USC00353692 & 42.5483 & -119.6556 & 1711.8 & OR & HART MTN REFUGE & \\
\hline USC00353770 & 45.4486 & -122.1547 & 228.0 & OR & HEADWORKS PORTLAND WTR & $\mathrm{HCN}$ \\
\hline USC00353827 & 45.3653 & -119.5639 & 574.5 & OR & HEPPNER & $\mathrm{HCN}$ \\
\hline USC00353995 & 43.9281 & -124.1069 & 35.1 & OR & HONEYMAN SP & \\
\hline USC00354003 & 45.6847 & -121.5175 & 152.4 & OR & HOOD RIVER EXP STN & $\mathrm{HCN}$ \\
\hline USC00354126 & 43.3708 & -122.9653 & 329.2 & OR & IDLEYLD PARK 4 NE & \\
\hline USC00354291 & 44.4233 & -118.9594 & 933.6 & OR & JOHN DAY & \\
\hline USC00354606 & 44.6253 & -122.7189 & 158.5 & OR & LACOMB 3 NNE & \\
\hline USC00354622 & 45.3167 & -118.0747 & 839.7 & OR & LA GRANDE & \\
\hline USC00354811 & 44.1014 & -122.6886 & 205.7 & OR & LEABURG $1 \mathrm{SW}$ & \\
\hline USC00354835 & 43.3597 & -122.2208 & 1242.7 & OR & LEMOLO LAKE 3 NNW & \\
\hline USC00355050 & 43.9144 & -122.7600 & 217.0 & OR & LOOKOUT POINT DAM & \\
\hline USC00355055 & 42.6722 & -122.6750 & 481.6 & OR & LOST CREEK DAM & \\
\hline USC00355142 & 44.6633 & -121.1461 & 744.6 & OR & MADRAS $2 \mathrm{~N}$ & \\
\hline USC00355160 & 43.9794 & -117.0247 & 688.8 & OR & MALHEUR BRANCH EXP STN & \\
\hline USC00355221 & 44.6125 & -121.9486 & 754.4 & OR & MARION FRKS FISH HATCH & \\
\hline USC00355593 & 45.9428 & -118.4089 & 295.7 & OR & MILTON FREEWATER & $\mathrm{HCN}$ \\
\hline USC00355711 & 44.8186 & -119.4200 & 608.1 & OR & MONUMENT 2 & \\
\hline USC00355734 & 45.4825 & -120.7236 & 570.0 & OR & MORO & $\mathrm{HCN}$ \\
\hline USC00356179 & 43.8764 & -116.9903 & 662.9 & OR & NYSSA & \\
\hline USC00356213 & 43.7428 & -122.4433 & 388.6 & OR & OAKRIDGE FISH HATCHERY & \\
\hline USC00356334 & 45.3558 & -122.6047 & 50.9 & OR & OREGON CITY & \\
\hline USC00356366 & 45.0333 & -123.9239 & 45.7 & OR & OTIS 2 NE & \\
\hline USC00356405 & 43.6500 & -117.2467 & 731.5 & OR & OWYHEE DAM & \\
\hline USC00356532 & 44.7275 & -121.2506 & 429.8 & OR & PELTON DAM & \\
\hline USC00356784 & 42.7519 & -124.5011 & 12.8 & OR & PORT ORFORD NO 2 & \\
\hline USC00356907 & 42.7342 & -122.5164 & 756.5 & OR & PROSPECT 2 SW & $\mathrm{HCN}$ \\
\hline USC00357169 & 42.9506 & -123.3572 & 207.3 & OR & RIDDLE & $\mathrm{HCN}$ \\
\hline USC00357277 & 43.3636 & -117.1142 & 1118.6 & OR & ROCKVILLE $5 \mathrm{~N}$ & \\
\hline USC00357331 & 43.2131 & -123.3658 & 129.5 & OR & ROSEBURG KQEN & $\mathrm{HCN}$ \\
\hline USC00357641 & 45.9869 & -123.9236 & 3.0 & OR & SEASIDE & \\
\hline USC00357675 & 44.1383 & -118.9750 & 1420.4 & OR & SENECA & \\
\hline USC00357817 & 43.1244 & -121.0620 & 1335.6 & OR & SILVER LAKE RS & \\
\hline USC00357823 & 45.0058 & -122.7739 & 124.4 & OR & SILVERTON & \\
\hline USC00358095 & 44.7892 & -122.8142 & 129.5 & OR & STAYTON & \\
\hline USC00358173 & 42.9592 & -120.7897 & 1277.7 & OR & SUMMER LAKE $1 \mathrm{~S}$ & \\
\hline USC00358536 & 43.2750 & -122.4497 & 627.9 & OR & TOKETEE FALLS & \\
\hline USC00358797 & 43.9814 & -117.2439 & 682.8 & OR & VALE & $\mathrm{HCN}$ \\
\hline USC00358884 & 45.8653 & -123.1903 & 190.5 & OR & VERNONIA NO 2 & \\
\hline USC00359316 & 43.6825 & -121.6875 & 1328.3 & OR & WICKIUP DAM & \\
\hline USC00450008 & 46.9658 & -123.8292 & 3.0 & WA & ABERDEEN & $\mathrm{HCN}$ \\
\hline USC00450482 & 45.7717 & -122.5286 & 86.6 & WA & BATTLE GROUND & \\
\hline
\end{tabular}


Table A1. Continued.

\begin{tabular}{|c|c|c|c|c|c|c|}
\hline ID & Latitude & Longitude & Elevation (m) & US state & Station name & Notes \\
\hline USC00450844 & 48.9947 & -117.3544 & 559.9 & WA & BOUNDARY DAM & \\
\hline USC00450945 & 47.1694 & -122.0036 & 208.8 & WA & BUCKLEY $1 \mathrm{NE}$ & $\mathrm{HCN}$ \\
\hline USC00451276 & 46.7200 & -122.9528 & 56.4 & WA & CENTRALIA & $\mathrm{HCN}$ \\
\hline USC00451350 & 47.8361 & -120.0381 & 335.0 & WA & CHELAN & \\
\hline USC00451400 & 47.9967 & -119.6483 & 254.2 & WA & CHIEF JOSEPH DAM & \\
\hline USC00451484 & 48.9672 & -122.3292 & 19.5 & WA & CLEARBROOK & $\mathrm{HCN}$ \\
\hline USC00451767 & 47.9544 & -118.9997 & 524.0 & WA & COULEE DAM $1 \mathrm{SW}$ & \\
\hline USC00451939 & 47.3706 & -123.1600 & 6.4 & WA & CUSHMAN POWERHOUSE 2 & $\mathrm{HCN}$ \\
\hline USC00452007 & 47.6575 & -118.1614 & 722.1 & WA & DAVENPORT & $\mathrm{HCN}$ \\
\hline USC00452157 & 48.7142 & -121.1431 & 271.6 & WA & DIABLO DAM & \\
\hline USC00452505 & 46.9692 & -120.5400 & 451.1 & WA & ELLENSBURG & $\mathrm{HCN}$ \\
\hline USC00452531 & 47.0092 & -123.4008 & 21.3 & WA & ELMA & \\
\hline USC00452548 & 48.0164 & -123.5906 & 109.7 & WA & ELWHA RS & \\
\hline USC00452675 & 47.9753 & -122.1950 & 18.3 & WA & EVERETT & $\mathrm{HCN}$ \\
\hline USC00452914 & 47.9558 & -124.3539 & 106.7 & WA & FORKS $1 \mathrm{E}$ & $\mathrm{HCN}$ \\
\hline USC00453515 & 47.4933 & -118.2500 & 658.4 & WA & HARRINGTON 1 NW & \\
\hline USC00453883 & 46.2447 & -118.8786 & 112.2 & WA & ICE HARBOR DAM & \\
\hline USC00454154 & 46.2111 & -119.1011 & 118.9 & WA & KENNEWICK & $\mathrm{HCN}$ \\
\hline USC00454338 & 46.8167 & -117.8831 & 449.9 & WA & LACROSSE & \\
\hline USC00454679 & 47.0022 & -118.5658 & 496.8 & WA & LIND 3 NE & \\
\hline USC00454748 & 46.3675 & -124.0378 & 7.6 & WA & LONG BEACH EXP STN & $\mathrm{HCN}$ \\
\hline USC00454764 & 46.7492 & -121.8120 & 841.9 & WA & LONGMIRE RAINIER NPS & $\mathrm{HCN}$ \\
\hline USC00454769 & 46.1506 & -122.9164 & 3.7 & WA & LONGVIEW & $\mathrm{HCN}$ \\
\hline USC00455224 & 47.1358 & -122.2558 & 176.5 & WA & MC MILLIN RSVR & $\mathrm{HCN}$ \\
\hline USC00455704 & 47.1414 & -121.9356 & 398.7 & WA & MUD MTN DAM & \\
\hline USC00456039 & 47.3328 & -118.6944 & 470.0 & WA & ODESSA & $\mathrm{HCN}$ \\
\hline USC00456096 & 48.6117 & -122.8064 & 24.4 & WA & OLGA 2 SE & $\mathrm{HCN}$ \\
\hline USC00456262 & 46.6092 & -121.6744 & 323.1 & WA & PACKWOOD & \\
\hline USC00456295 & 47.3058 & -121.8514 & 280.4 & WA & PALMER 3 ESE & \\
\hline USC00456534 & 47.7850 & -120.6456 & 590.1 & WA & PLAIN & \\
\hline USC00456789 & 46.7603 & -117.1861 & 766.6 & WA & PULLMAN 2 NW & $\mathrm{HCN}$ \\
\hline USC00456846 & 47.8092 & -122.9136 & 37.5 & WA & QUILCENE 2 SW & \\
\hline USC00456880 & 47.2156 & -119.8478 & 388.3 & WA & QUINCY $1 \mathrm{~S}$ & \\
\hline USC00456898 & 46.7858 & -121.7425 & 1654.1 & WA & RAINIER PARADISE RS & \\
\hline USC00456974 & 48.6469 & -118.7314 & 798.6 & WA & REPUBLIC & \\
\hline USC00457059 & 47.1178 & -118.3722 & 566.9 & WA & RITZVILLE 1 SSE & $\mathrm{HCN}$ \\
\hline USC00457180 & 47.2325 & -117.3625 & 733.0 & WA & ROSALIA & \\
\hline USC00457185 & 48.7272 & -121.0722 & 376.7 & WA & ROSS DAM & \\
\hline USC00457267 & 47.0933 & -117.5878 & 595.0 & WA & ST. JOHN & $\mathrm{HCN}$ \\
\hline USC00457507 & 48.4958 & -122.2355 & 18.3 & WA & SEDRO WOOLLEY & $\mathrm{HCN}$ \\
\hline USC00457696 & 45.6228 & -122.2175 & 134.1 & WA & SKAMANIA FISH HATCHRY & \\
\hline USC00458773 & 45.6778 & -122.6511 & 64.0 & WA & VANCOUVER 4 NNE & $\mathrm{HCN}$ \\
\hline USC00459200 & 46.0436 & -118.4628 & 192.6 & WA & WHITMAN MISSION & \\
\hline USC00459376 & 48.4742 & -120.1886 & 533.1 & WA & WINTHROP 1 WSW & $\mathrm{HCN}$ \\
\hline USW00024130 & 44.8428 & -117.8086 & 1024.4 & OR & BAKER CITY MUNI AP & $\mathrm{HCN}$ \\
\hline USW00024131 & 43.5667 & -116.2406 & 857.7 & ID & BOISE AIR TERMINAL & $\mathrm{GSN}^{\mathrm{b}}, \mathrm{WMO} 72681^{\mathrm{c}}$ \\
\hline USW00024133 & 42.5417 & -113.7661 & 1262.5 & ID & BURLEY MUNI AP & \\
\hline USW00024141 & 47.3078 & -119.5153 & 381.6 & WA & EPHRATA MUNI AP & WMO 72790 \\
\hline USW00024149 & 46.3747 & -117.0156 & 437.7 & ID & LEWISTON NEZ PERCE CO AP & HCN, WMO 72783 \\
\hline USW00024155 & 45.6906 & -118.8528 & 461.8 & OR & PENDLETON & GSN, WMO 72688 \\
\hline USW00024156 & 42.9203 & -112.5711 & 1364.9 & ID & POCATELLO RGNL AP & GSN, WMO 72578 \\
\hline USW00024157 & 47.6217 & -117.5281 & 717.2 & WA & SPOKANE INTL AP & HCN, WMO 72785 \\
\hline USW00024162 & 44.0206 & -117.0128 & 667.5 & OR & ONTARIO MUNI AP & \\
\hline USW00024219 & 45.6194 & -121.1661 & 71.6 & WA & THE DALLES MUNI AP & \\
\hline USW00024221 & 44.1278 & -123.2206 & 107.6 & OR & EUGENE MAHLON SWEET AP & WMO 72693 \\
\hline USW00024225 & 42.3811 & -122.8722 & 395.3 & OR & MEDFORD ROGUE VLY AP & WMO 72597 \\
\hline USW00024227 & 46.9733 & -122.9033 & 57.3 & WA & OLYMPIA AP & GSN, WMO 72792 \\
\hline
\end{tabular}


Table A1. Continued.

\begin{tabular}{lrrrlll}
\hline ID & Latitude & Longitude & Elevation $(\mathrm{m})$ & US state & Station name & Notes \\
\hline USW00024229 & 45.5908 & -122.6003 & 5.8 & OR & PORTLAND INTL AP & WMO 72698 \\
USW00024232 & 44.9050 & -123.0011 & 62.5 & OR & SALEM MCNARY FLD & WMO 72694 \\
USW00024233 & 47.4444 & -122.3139 & 112.8 & WA & SEATTLE TACOMA INTL AP & WMO 72793 \\
USW00024242 & 45.5511 & -122.4089 & 8.8 & OR & PORTLAND TROUTDALE AP & WMO 72781 \\
USW00024243 & 46.5683 & -120.5428 & 324.3 & WA & YAKIMA AIR TERMINAL & HCN \\
USW00024284 & 43.4133 & -124.2436 & 5.2 & OR & NORTH BEND RGNL AP & HCN, WMO 72791 \\
USW00094224 & 46.1569 & -123.8825 & 2.7 & OR & ASTORIA RGNL AP & \\
USW00094225 & 46.9728 & -123.9303 & 3.7 & WA & HOQUIAM BOWERMAN AP & \\
USW00094239 & 47.3978 & -120.2014 & 374.6 & WA & WENATCHEE PANGBORN AP & WMO 72797 \\
USW00094240 & 47.9375 & -124.5550 & 56.4 & WA & QUILLAYUTE STATE AP & WPMTATH
\end{tabular}

a indicates the station is included in the US Historical Climatology Network (HCN); ${ }^{b}$ indicates the station is included in the Global Climate Observing System (GCOS) Surface Network (GSN); ${ }^{\mathrm{c}}$ denotes the Word Meteorological Organization (WMO) number for the station.

\section{References}

Abatzoglou, J., Redmond, K., and Edwards, L.: Classification of regional climate variability in the state of California, J. Appl. Meteorol., 48, 1527-1541, doi:10.1175/2009JAMC2062.1, 2009.

Ancell, B. and Hakim, G.: Comparing Adjoint-and EnsembleSensitivity Analysis with Applications to Observation Targeting, Mon. Weather Rev., 135, 4117-4134, doi:10.1175/2007MWR1904.1, 2007.

Bergot, T., Hello, G., Joly, A., and Malardel, S.: Adaptive Observations: A Feasibility Study, Mon. Weather Rev., 127, 743-765, 1999.

Bishop, C. and Toth, Z.: Ensemble transformation and adaptive observations, J. Atmos. Sci., 56, 1748-1765, doi:10.1175/15200469(1999)056<1748:ETAAO > 2.0.CO;2, 1999.

Dabberdt, W. and Schlatter, T.: Research opportunities from emerging atmospheric observing and modeling capabilities, B. Am. Meteorol. Soc., 77, 305-323, 1996.

Daly, C., Gibson, W., Taylor, G., Johnson, G., and Pasteris, P.: A knowledge-based approach to the statistical mapping of climate, Clim. Res., 22, 99-113, 2002.

Fujioka, F.: A method for designing a fire weather network, J. Atmos. Ocean. Tech., 3, 564-570, 1986.

Hamill, T.: Ensemble-based atmospheric data assimilation, Cambridge Univ. Press, New York, 124-156, 2006.

Hargrove, W., Hoffman, F., and Law, B.: New analysis reveals representativeness of the AmeriFlux network, Eos, 84, 529-535, 2003.

Huntley, H. and Hakim, G.: Assimilation of time-averaged observations in a quasi-geostrophic atmospheric jet model, Clim. Dynam., 35, 995-1009, doi:10.1007/s00382-009-0714-5, 2010.
Kalman, R.: A new approach to linear filtering and prediction problems, J. Basic Eng., 82, 35-45, 1960.

Khare, S. and Anderson, J.: A methodology for fixed observational network design: theory and application to a simulated global prediction system, Tellus A, 58, 523-537, 2006.

Lawrimore, J. H., Menne, M. J., Gleason, B. E., Williams, C. N., Wuertz, D. B., Vose, R. S., and Rennie, J.: An overview of the Global Historical Climatology Network monthly mean temperature data set, version 3 (1984-2012), J. Geophys. Res.-Atmos., 116, D19121, doi:10.1029/2011JD016187, 2011.

Lundquist, J. and Cayan, D.: Surface temperature patterns in complex terrain: Daily variations and long-term change in the central Sierra Nevada, California, J. Geophys. Res., 112, D11124, doi:10.1029/2006JD007561, 2007.

Mesinger, F., DiMego, G., Kalnay, E., Mitchell, K., Shafran, P., Ebisuzaki, W., Jovic, D., Woollen, J., Rogers, E., Berbery, E., Ek, M., Fan, Y., Grumbine, R., Higgins, W., Li, H., Lin, Y., Manikin, G., Parrish, D., and Shi, W.: North American regional reanalysis, B. Am. Meteorol. Soc., 87, 343-360, doi:10.1175/BAMS-87-3343, 2006.

Morss, R., Emanuel, K., and Snyder, C.: Idealized adaptive observation strategies for improving numerical weather prediction, J. Atmos. Sci., 58, 210-232, 2001.

Potter, J. E.: W matrix augmentation, M.I.T. Instrumentation Laboratory Memo SGA 5-64, Massachusetts Institute of Technology, Cambridge, MA, 1964. 